\title{
A Study of Critical Flicker Fusion Threshold among Smartphone Users
}

\author{
Diksha Gautam ${ }^{1}$ and Deepa Vinay ${ }^{2}$ \\ ${ }^{1}$ Departmentof Family Resource Management, College of Home Science, \\ A.N.D.U.A.\&T., Kumarganj, Ayodhya, U.P., India \\ ${ }^{2}$ Department of Family Resource Management, College of Home Science, \\ G.B.P.U.A.\& T., Pantnagar, Uttarakhand, India \\ *Corresponding author
}

\begin{abstract}
A B S T R A C T
The critical flicker fusion frequency (CFF) is the frequency at which a flickering stimulus is perceived to be constant; the quick recognition of variation in stimuli indicates the active coordination between eyes and brain. When human eyes get exposed to the light radiating from Smartphone screen for longer period that driven us into recognizable mental and visual fatigue results in sleep disturbances, mood fluctuations, insomnia, dry eyes, computer vision syndrome, misconceptions and tactile hallucinations. In the present study the CFF frequency test has been used to evaluate the mental and visual fatigue due to continuous Smartphone overuse. Total 160 respondents ( 80 girls and 80 boys) of 18 to 24 years age group were randomly selected for baseline data out of which 10 percent i.e. 16 ( 8 girls and 8 boys) respondents were selected to assess the change in critical flicker fusion (CFF) frequency among the Smartphone users before and after usage. Critical fusion frequency was recorded by Flicker Fusion Apparatus. The findings of the study showed that there was slight decrease in fusion and flicker frequency in both eyes of the respondents that indicated the visual fatigue in the respondents due to Smartphone use for longer period. There was no significant difference between before and after case of CFFF rate in participants. Decreased CFF frequency after using Smartphone indicated visual and mental fatigue in participants. The slight variation in CFFF rate may not giving instant effect but indicated the point of concern for heavy Smartphone users as its impact will be emerge in later phase of life.
\end{abstract}

\section{Introduction}

In this technological era, we are surrounded with may electronic gadgets Smartphone is one of the most popular technology among them that can keep people connected with the world at their fingertips that results in longer exposure to that LED light emitting device that leads to negative consequences on the users therefore it becomes an important public health issue and creating alarming situation especially for the college going students.

Critical flicker fusion frequency (CFFF) is the frequency at which an intermittent light stimulus appears to be completely steady to 
the observer (As defined by Encyclopedia of psychopharmacology). The Critical Flickering Fusion frequency (CFFF) test measures the rate at which successively presented light stimuli appear to be steady and continuous. This rate, expressed in $\mathrm{Hz}$, is commonly referred to as the "threshold frequency". Normal adult Critical flicker frequency reportedly is around 35 to 40 Hertz.

Critical flicker fusion is the highest frequency at which subjects are unable to perceive flickering. It is used as an indicator of physical human fatigue, mental workload, and cognitive function as well. In medicine and physiology, experimental evidence demonstrated the relationships between the CFFF level and individual human attributes like age, sex, intelligence and job experience. Increased Smartphone usage leads to mental and visual fatigue that can be caused by viewing a digital screen it often depends on the amount of time spent continuous looking at a digital screen that resulted the high visual demand of digital screen. Hence the present study was an attempt to find out the CFF frequency rate in Smartphone users and to estimate the change in CFF frequency before and after Smartphone usage among users.

\section{Materials and Methods}

The study was conducted in G.B. Pant University, Pantnagar, Udhamsingh Nagar district of Uttarakhand. 160 respondents $(80$ girls and 80 boys) were randomly selected for experimental data out of which 10 percent i.e. 16 ( 8 girls and 8 boys) respondents of $18-24$ years age group were selected to assess the change in CFF frequency among the participants before and after 30 minute of Smartphone usage.

\section{Critical flicker fusion test}

CFFFR was measured with a Digital Flicker value tester to examine the visual strain. In this tester, the system presents a series of green and red light stimuli at different frequencies adjusted from $20-120 \mathrm{~Hz}$. Red/green light stimuli were surrounded by a white funnel shaped plastic cover for focus. After pre requisites, each participant was informed well about the procedure. Each participant was seated in front of this apparatus i.e. $80 \mathrm{cms}$ from the stimulus in a semi-dark room with a single $40-\mathrm{w}$ bulb set behind the participant. After that the frequency of flicker was gradually increased from a minimum threshold of $20 \mathrm{~Hz}$ till the participants reported that they perceived successively presented light stimuli to be "constant" or "steady". The threshold perceived by the participants was obtained. This provides an indication of the "critical" frequency, i.e. the highest frequency at which participants are unable to perceive flickering. After getting the fusion threshold the frequency was gradually decreased till the participant reported that they again perceived successively presented light stimuli to be "flickering" or "vibrating"

\section{Results and Discussion}

\section{Critical flicker fusion frequency rate}

Human eyes can detect flickering light for certain frequency, as the frequency increased and reach the threshold, human eyes cannot distinguish that the light is flickering for longer duration of time, and then light seem as fused. This process of detection is known flicker fusion. This is commonly referred to as the "threshold frequency" and it is expressed in Hz. Identifying human capability in detection of the threshold where human cannot differentiate flicker and fusion is important, particularly in designing electronic devices where light is used (Bharathi and Reddy, 2015) whereas in another study Gangopadhayay et al., (2013) reported that normal human eye can perceive a frequency of $60 \mathrm{~Hz}$. This test is widely used to study the 
human behaviour, visual fatigue and visual strain since it is easy to administer and relatively non-invasive (Green and Bavelier, 2006).

The state, at which an intermittent light becomes less distinct and fuses, is recognized as the ascending critical fusion threshold. On the other hand, the alteration of perceptual state from a continuous supra-threshold light to an intermittent one is referred to as the descending critical flicker frequency threshold (Yung, 2016). Therefore the average of ascending and descending thresholds is critical flicker fusion threshold (Curran and Wattis, 1998). The critical flicker fusion threshold (CCFT) is often used as measure for current state of the central nervous system of an individual.

The above table shows the CFF frequency rate of the respondents in green light girls and boys have $38.5 \pm 2.75$ and $38.4 \pm 3.29$ fusion frequency in left eye whereas $38.5 \pm 2.46$ and $38.3 \pm 2.97$ in right eyes. Girls and boys have $35.8 \pm 2.71$ and $35.7 \pm 3.27$ flicker frequency in left eye whereas $35.9 \pm 2.53$ and $35.8 \pm 3.16$ in right eyes.
The above table shows the CFF frequency rate of the respondents in red light girls and boys have $39.5 \pm 2.58$ and $39.0 \pm 2.98$ fusion frequency in left eye whereas $39.5 \pm 2.55$ and $39.2 \pm 3.13$ in right eyes. Girls and boys have $36.3 \pm 4.26$ and $36.3 \pm 3.29$ flicker frequency in left eye whereas $36.8 \pm 2.74$ and $36.2 \pm 3.44$ in right eyes. Bharathi and Reddy (2015) reported that normal adult Critical flicker frequency reportedly is around 36 to 39 Hertz. The range of critical flicker fusion frequency is similar to the present study. The above table shows before and after mean values of Critical Flicker Fusion frequency Rate of respondents in green light. After continues use of the Smartphone for 30 minutes in left eye fusion frequency was $36.90 \pm 2.17$ and flicker frequency was $35.28 \pm 2.35$ and in right eye fusion frequency was $36.49 \pm 1.91$ and flicker frequency was $35.20 \pm 1.82$. The above data clearly shows the slight decrease in both frequencies in after case that indicates the visual and mental fatigue in the respondents after using Smartphone continues for 30 minutes. Gangopadhayay et al., (2013) also reported in his study that decline in CFF frequency threshold shows marked fatigue in the individual.

Table.1 Average critical flicker fusion frequency rate of participants rate in green light

\begin{tabular}{|c|c|c|c|c|}
\hline & \multicolumn{4}{|c|}{ Green Light } \\
\hline & \multicolumn{2}{|c|}{ Left Eye } & \multicolumn{2}{|c|}{ Right Eye } \\
\hline & $\begin{array}{c}\text { Fusion } \\
\text { frequency }\end{array}$ & $\begin{array}{c}\text { Flicker } \\
\text { frequency }\end{array}$ & $\begin{array}{c}\text { Fusion } \\
\text { frequency }\end{array}$ & $\begin{array}{c}\text { Flicker } \\
\text { frequency }\end{array}$ \\
\hline Girls & $38.5 \pm 2.75$ & $35.8 \pm 2.71$ & $38.5 \pm 2.46$ & $35.9 \pm 2.53$ \\
\hline Boys & $38.4 \pm 3.29$ & $35.7 \pm 3.27$ & $38.3 \pm 2.97$ & $35.8 \pm 3.16$ \\
\hline
\end{tabular}

Table.2 Average critical flicker fusion frequency rate of participants in red light $(n=160)$

\begin{tabular}{|c|c|c|c|c|}
\hline & \multicolumn{4}{|c|}{ Red Light } \\
\hline & \multicolumn{2}{|c|}{ Left Eye } & \multicolumn{2}{|c|}{ Right Eye } \\
\hline & $\begin{array}{c}\text { Fusion } \\
\text { frequency }\end{array}$ & $\begin{array}{c}\text { Flicker } \\
\text { frequency }\end{array}$ & $\begin{array}{c}\text { Fusion } \\
\text { frequency }\end{array}$ & $\begin{array}{c}\text { Flicker } \\
\text { frequency }\end{array}$ \\
\hline Girls & $39.5 \pm 2.58$ & $36.3 \pm 4.26$ & $39.5 \pm 2.55$ & $36.8 \pm 2.74$ \\
\hline Boys & $39.0 \pm 2.98$ & $36.3 \pm 3.29$ & $39.2 \pm 3.13$ & $36.2 \pm 3.44$ \\
\hline
\end{tabular}


Table.3 Difference in before and after mean values of critical flicker fusion frequency rate of participants in green light

\begin{tabular}{|c|c|c|c|c|c|}
\multicolumn{2}{|c|}{ Left Eye } & \multicolumn{2}{c|}{ Right Eye } \\
\cline { 3 - 6 } & & \multicolumn{2}{|c}{$=16)$} \\
\hline \multirow{2}{*}{ Girls } & Before & $39.86 \pm 3.36$ & $37.86 \pm 2.95$ & $39.60 \pm 2.44$ & $37.74 \pm 1.68$ \\
\cline { 2 - 6 } & After & $36.90 \pm 2.17$ & $35.28 \pm 2.35$ & $36.49 \pm 1.91$ & $35.20 \pm 1.82$ \\
\hline \multirow{2}{*}{ Boys } & Before & $37.89 \pm 1.82$ & $35.08 \pm 3.32$ & $38.38 \pm 2.83$ & $36.06 \pm 3.49$ \\
\cline { 2 - 6 } & After & $36.95 \pm 1.62$ & $34.28 \pm 2.70$ & $37.15 \pm 1.90$ & $34.30 \pm 2.86$ \\
\hline
\end{tabular}

Table.4 Difference in before and after mean values of critical flicker fusion frequency rate of participants in red light

\begin{tabular}{|c|c|c|c|c|c|}
\hline \multicolumn{2}{|c|}{} & \multicolumn{2}{|c|}{ Left Eye } & \multicolumn{2}{c|}{ Right Eye } \\
\cline { 3 - 6 } & & $\begin{array}{c}\text { Fusion } \\
\text { frequency }\end{array}$ & $\begin{array}{c}\text { Flicker } \\
\text { frequency }\end{array}$ & $\begin{array}{c}\text { Fusion } \\
\text { frequency }\end{array}$ & $\begin{array}{c}\text { Flicker } \\
\text { frequency }\end{array}$ \\
\hline \multirow{2}{*}{ Girls } & Before & $39.38 \pm 3.09$ & $36.98 \pm 2.21$ & $39.64 \pm 2.63$ & $37.68 \pm 2.23$ \\
\cline { 2 - 6 } & After & $37.75 \pm 2.64$ & $36.34 \pm 2.60$ & $37.75 \pm 2.35$ & $36.28 \pm 2.42$ \\
\hline \multirow{2}{*}{ Boys } & Before & $38.95 \pm 3.56$ & $35.96 \pm 3.85$ & $38.75 \pm 2.48$ & $36.09 \pm 3.43$ \\
\cline { 2 - 6 } & After & $39.24 \pm 2.69$ & $35.98 \pm 3.26$ & $39.21 \pm 2.08$ & $36.18 \pm 2.90$ \\
\hline
\end{tabular}

Table.5 Effect of CFF value before and after use of Smartphone in green light source

\begin{tabular}{|c|c|c|c|c|}
\hline & & \multicolumn{3}{|c|}{ Green light } \\
\hline & & CFF threshold (Hz) & t-value & p value \\
\hline \multirow[t]{2}{*}{ Girls } & Before & $38.77 \pm 2.61$ & \multirow[t]{2}{*}{2.2213} & \multirow[t]{2}{*}{$0.9691^{\mathrm{NS}}$} \\
\hline & After & $35.97 \pm 1.92$ & & \\
\hline \multirow[t]{2}{*}{ Boys } & Before & $36.85+2.68$ & \multirow[t]{2}{*}{0.99751} & \multirow[t]{2}{*}{$0.8241^{\mathrm{NS}}$} \\
\hline & After & $35.67+2.08$ & & \\
\hline
\end{tabular}

Table.6 Effect of CFF value before and after use of Smartphone in red light source

\begin{tabular}{|c|c|c|c|c|}
\hline & & \multicolumn{3}{|c|}{ Red light } \\
\hline & & CFF threshold (Hz) & t-value & p value \\
\hline \multirow[b]{2}{*}{ Girls } & Before & $38.42 \pm 2.41$ & \multirow[t]{2}{*}{-1.0366} & \multirow[t]{2}{*}{$0.1672^{\mathrm{NS}}$} \\
\hline & After & $37.03 \pm 2.28$ & & \\
\hline \multirow[t]{2}{*}{ Boys } & Before & $37.44 \pm 3.17$ & \multirow[t]{2}{*}{0.13037} & \multirow[t]{2}{*}{$0.55^{\mathrm{NS}}$} \\
\hline & After & $37.65 \pm 2.54$ & & \\
\hline
\end{tabular}

${ }^{N S}$ denotes Non significant at $5 \%$ level 


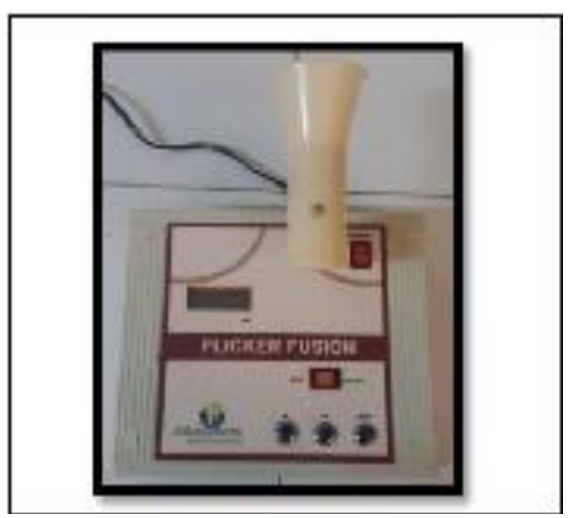

Fig.1 Flicker Fusion

Generally, an increase in CFF threshold is reflective of an increase in cortical arousal and sensory sensitivity. A decrease in CFF threshold may indicate a reduced efficiency of the sensory system to process information (Davranche \& Pichon, 2005).

The above table shows before and after mean values of Critical flicker fusion frequency Rate of participants in red light stimuli. The above data clearly shows there was no decline in both frequencies in red light that not depicts any visual fatigue in the respondents after using Smartphone continues.

Table reported the result of comparison of CFFFR value in green light source before and after 30 minutes Smartphone usage. Mean value of both eyes among respondents It showed that the CFF threshold value of before was slightly higher than the after case. The $t$ value showed the significant difference between the CFFFR value of before and after case. Therefore it can be said that there was no significant effect of green light source before and after on respondents using Smartphone for 30 minute continuously.

Data showed in the table reported the result of comparison of CFF value of before and after of the respondents in red light source. Mean value of the before and after was $38.42 \pm 2.41$ and $37.03 \pm 2.28$ respectively. It showed that the $\mathrm{CFF}$ threshold value was slightly

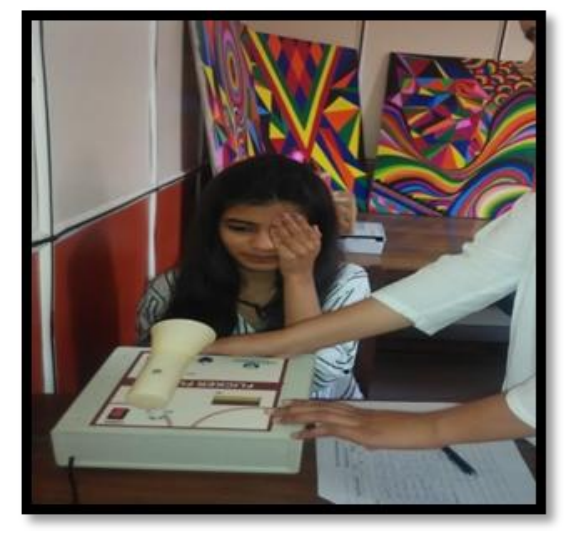

Fig.2 Performing CFF test

decreased after Smartphone use in girls only. The decrease in critical flicker fusion frequency means that the brain is less active. The critical flicker fusion threshold (CFFT) is often used as a measure of the current state of the central nervous system of an individual. Therefore, decrease in frequency threshold shows marked fatigue in the individual (Gangopadhayay et al., 2013). The t value (1.0366) showed the non-significant difference between the CFF value of girls in before and after case while using Smartphone for 30 minute continuously.

It can be concluded that Smartphone use for 30 minutes cannot affect the CFF threshold value; the reason may be the short duration of experiment. The result of the present study is opposite with the study conducted by Endukuru et al., (2015) to examined the video games effect on Critical flickering fusion frequency rate. The findings of the study showed that CFFFR threshold increases significantly in media players when compared to non-media players $(\mathrm{p}<0.001)$.

In conclusion, CFF test is reliable, quick and non invasive measure that is mainly used to recognize physiological and pathological stress situations as well as measuring fatigue of the central nervous system. It indicates the mental workload and variation in visual perception. The findings of the study indicate that the continuous screen time of 
Smartphone may decrease the CFFF rate that shows marked fatigue in participants. It is well and good if the problem can be identified at the initial stage. The slight variation in CFFF rate due to heavy usage of Smartphone may do not give immediate effect the functioning of brain and eyes but as the screen time increases the fatigue will turn into major risks in future.

\section{References}

Bharathi, C.K. and Reddy, K. P. 2015. Measuring Critical Flicker Fusion Frequency in Human Eye by Utilizing Sound Card of the Computer as DAC. International Journal for Research in Applied Science \& Engineering. 3(1):48-50.

Curran, S., and Wattis, J. P. 1998. Critical flicker fusion threshold: A useful research tool in patients with Alzheimer's Disease. Human Psychopharmacology, 13:337-355

Davranche, K. and Pichon, A. 2005. Critical flicker frequency threshold increment after exhanding exercise, Journal of Sport and Exercise Psychology, 27(4): 515-520

Endukuru, C.K., Maruthy, K.N. and Deepthi,
T.S., 2015. A Study of Critical Flickering Fusion Frequency Rate in Media Players. International Journal of Multidisciplinary Research and Development. 2(5):499-502.

Endukuru, C.K., Maruthy, K.N. and Deepthi, T.S., 2016. A study of Critical Flickering Fusion Frequency Rate in Media Players. International Journal of Physiology, 4(1):144-148.

Gangopadhyay, S., Chakrabarty S. and Banerjee S. 2015. Assessment of Mental Fatigue among Chikan Embroidery Workers of West Bengal, Ergonomics for Rural Development. 332-340

Green, C. S. and Bavelier, D. 2006. Effect of Action Video Games on the Spatial Distribution of Visuospatial Attention. Journal of Experimental Psychology: Human Perception and Performance, 32(6): 1465-1478

Shankar, H., Pesudovs, K. 2007. Critical flicker fusion test of potential vision. Journal of Cataract Refractive Surgery.33:232-239

Yung, M. 2016. Fatigue at the Workplace: Measurement and Temporal Development, Thesis, University of Waterloo.

\section{How to cite this article:}

Diksha Gautam and Deepa Vinay. 2020. A Study of Critical Flicker Fusion Threshold among Smartphone Users. Int.J.Curr.Microbiol.App.Sci. 9(03): 2381-2386.

doi: https://doi.org/10.20546/ijcmas.2020.903.271 